\title{
Variation in the pronunciation/silence of the prepositions in locative determiners
}

\author{
Anna Maria Di Sciullo*
}

\begin{abstract}
We argue that the micro-variation observed in the pronunciation/silence of the prepositional head of locative determiners in Fallese, a dialect spoken in Abruzzi, follows from the option of valuing features by either External Merge or by Internal Merge, given Spell-Out conditions, whereas this option is not available in English and Italian. It follows that the prepositional head is silent in Italian and English, whereas it can be pronounced in Fallese when the Specifier of the locative determiner is not filled. We show that this feature-based approach to micro-variation, in conjunction with principles of efficient computation, makes correct predictions for the pronunciation of the prepositional head in other functional categories, as well as it makes predictions on the diachronic development of locative determiners Latin to Fallese and from Latin to Italian', otherwise it looks like Fallese is an old stage of Italian.
\end{abstract}

Keywords. locative determiners; prepositions; language variation; pronunciation; merge; third factor principles

1. Introduction. Variation in the linear order as well as in the pronunciation/silence of linguistic constituents is observed cross-linguistically. We assume that the computational procedure of the Language Faculty (Merge, feature valuing, etc.) in conjunction with principles of efficient computation (pronounce the minimum, derivation by phases, no tampering condition, etc.) gives rise to language variation brought about by experience (language acquisition and languages in contact) (Chomsky 2005). We further assume further that micro-variation is tied to the properties of lexical items, functional heads and other constituents (Chomsky 1981, 1995; Kayne 2005, 2006, 2012; Liao \& Shi 2013, a.o.). We focus on locative determiners in Fallese, a dialect spoken in Abruzzi, where the preposition $a$ can be pronounced in some cases, (a)ecche 'here', (a)locche 'there', (1), whereas it must be pronounced in other cases, (2). This micro-variation is neither observed in Italian (qui/la), nor in English.

a. Minghe sta (a)ecch (Fa.)/qui. (It.)

Minghe is at-here / here

'Minghe is here.'

b. $\quad$ Minghe sta (a)locche (Fa)/ lì. (It.)

Minghe is at-there / there

'Minghe is there.'

(2) a. Gianni è arrivato *(a)locche (Fa.)/lì. (It.)

Gianni is arrived at-there / there

'Gianni arrived there.'

\footnotetext{
* Author: Anna Maria Di Sciullo, University of Quebec in Montreal and New York University (di sciullo.annemarie@uqam.ca). Many thanks to the audiences at the NYU Broun Bag series, at the Annual meeting of the LSA, Austin Texas, and at the Stony Brook Linguistic Colloquium for their comments on a previous version of this paper. This work was supported in part by funding from the Fonds de recherche du Québec for the Research on Dynamic Interfaces, grant number 137253. www.interfaceasymmetry.uqam.ca; www.biolinguistics.uqam.ca
} 
b. Gianni è andato *(a)locche (Fa) lì. (It.)

Gianni is went at there / there

'Gianni went there.'

More complex locative determiners that include a locative noun, alocche a bal 'down there' and alocche a monte 'up there', also show variation in the pronunciation/silence of the preposition $a$ associated with the locative determiner, but not with the one associated with the locative noun bal (lit. valley) or monte (lit. mount), (3). This micro-variation is not observed neither Italian nor in English.

(3) a. Minghe sta (a)locche *(a)bal (Fa) / lì giù. (It.)

Minghe is at-there at valley / there down

'Minghe is down there.'

b. Minghe sta (a)locche *(a)monte (Fa)/ lì su. (It.)

Minghe is at-there at mountain / there up

'Minghe is up there.'

From a typological perspective, the form of locative determiners in Fallese is closer to Latin than to their Italian counterparts, (4). Latin locative determiners are PPs with an overt prepositional head $a d$ (at). This preposition is no longer pronounced in Italian, whereas it can be pronounced in Fallese in some cases, as we illustrated in (1)-(3) above. This is also the case for the wh-locative PP, (5), as well as for the PP Place, (6).

(4)

$$
\begin{array}{ll}
\text { a. } & \text { abbal (Fa.) } \\
\text { b. } & \text { ammown (valley)' } \\
& \text { 'up (mount)' }
\end{array}
$$

qui (It.)
'here'
la/lì (It.)
'there'
la/li (It.)
'there'
dove (It.)
'where'
la/li giu (It.)
'down there'
la/li su (It.)
'up there'

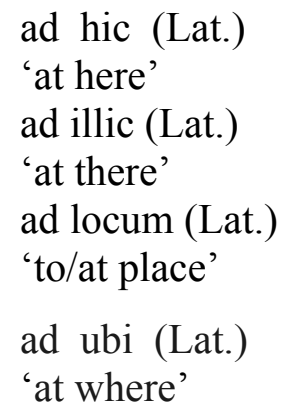

These facts from Fallese have never been analyzed in a generative framework, to our knowledge. We will attempt to provide an analysis of the facts that offers an explanation of the microvariation. We thus raise the following questions: How do the facts follow from the theory? What do they tell us about language and variation?

We argue that the micro-variation in the pronunciation/silence of the prepositional head in Fallese locative determiners follows from a difference in feature valuation by Internal or External Merge (Chomsky 2001), given principles of efficient computation, including derivation by phases (Chomsky 2008) and Spell-Out Conditions (Di Sciullo 2005, Collins 2007). It follows that the prepositional head of the locative determiner is silent in Italian, whereas it must be pronounced in Fallese when the Specifier of the PP is not filled. The proposed analysis brings further support to the view that micro-variation is tied to specific features and lexical items, as 
well as it brings further understanding of the role of third factor principles in language variation.

This paper unfolds as follows. We first discuss previous works on locative determiners in English here and there, and we raise open questions left unanswered. Secondly, we formulate an analysis of the facts that derives the micro-variation from a minimal difference in the computational procedure of the language faculty. Thirdly, we identify the predictions of the analysis for other functional categories in Fallese and Italian, as well as for the diachronic development of locative determiners in Italian. Lastly, we draw consequences for the theory of variation.

2. Locative determiners in English. In the spirit of Katz and Postal (1964), Kayne (2004, 2005) proposed that here and there contain an unpronounced noun PLACE corresponding to overt place, as in [there PLACE]. ${ }^{1}$ Collins (2007) assumes further that here and there can be accompanied by unpronounced prepositions. In (7) the locative (AT) and directional (TO) prepositions are capitalized to indicate that they can be unpronounced even though they are part of the syntax of locative determiners as well as of their semantics.

\section{[AT/TO here PLACE], [AT/TO there PLACE], [AT/TO where PLACE]}

Notwithstanding the fact that the prepositional head is not pronounced, as it is the case in English for example, here and there are PPs and not of DPs. Thus, here and there may occur in the complement position of locative and directional verbs, where the complement is a PP and not a DP. They can be questioned by wh-PP and not wh-DPs. They can be conjoined with PPs, and not with DPs. I will assume that they are PPs in English, and that an unpronounced preposition $\mathrm{AT} / \mathrm{TO}$ is part of their syntactic derivation.

It is worth noting that this is also the case when here and there are in the domain of another preposition such as near, which might prima facie suggest that they are DPs and not PPs. However, a preposition can be pronounced in these contexts as well, as in they stayed near (to) there. Furthermore, the preposition is stranded in wh-questions, as in where did they stay/go near to? vs. *where did they go near? This also indicates that near takes a PP complement.

Collins (2007) argues that the silence of the preposition AT/TO in English here and there follows from a more general version of the Doubly-Filled Comp Filter (Koopman and Szabolcsi 2000), restated in terms of a Spell-Out condition, (8).

a. $\quad$ Edge $(\mathrm{X})$ must be phonetically overt.

b. The condition in (a) applies in a minimal way so that either the head or the specifier, but not both, are spelled-out overtly.

(Collins 2007)

The Edge $(\mathrm{X})$ of a phase includes both X (the Head) and the Specifier of X in [Spec[H[Compl ]]]. Only the edge of a phrase is accessible from outside and the complement of a phase is spelled out before the edge. In the theory of cyclic spell-out (Chomsky 2008), the edge of a strong phrase (the Head and the Specifier) is spelled-out at a later point in the derivation than the complement. This implies that for strong phrases there can be no interaction at the time of spell-out between the members of the edge and the complement:

\footnotetext{
${ }^{1}$ Expressions such as here and there along with other expressions including quantifiers, such as someone and something have been referred to as 'r-pronouns' in Van Reimsdijk (1978) since the set of expressions he targeted in Dutch finished with ' $r$ '. Kayne (2005) as well as Collins (2007) referred to them as 'r-determiners ', since pronouns are determiners (Postal 1966). We will refer to expressions such as here and there in English as well as in other languages as locative determiners as they include a prepositional head that is unpronounced in some cases.
} 


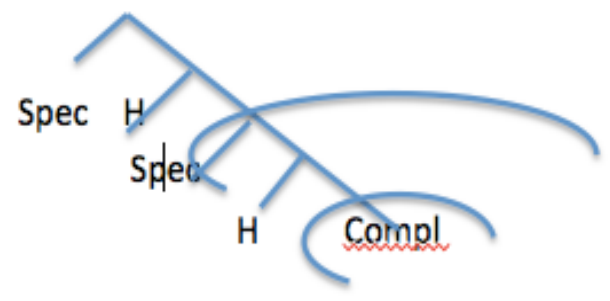

The Condition in (8) reduces the choice in the pronunciation of the categories at the edge of a phase, the Head or the Specifier. To this extent, I will consider this condition to be part of the third factor principles or part of the principles of efficient computation. ${ }^{2}$

According to Collins (2007), when here/there are in argument position (e.g. John stayed/went there), the locative determiner obligatorily moves to the Specifier of AT/TO in English, $(9 \mathrm{a}, \mathrm{b})$. If here/there is in the Specifier of AT/TO then the prepositional Head will not be pronounced, (9c). If there/there subsequently moves to a higher position, then AT/TO will be pronounced. When here/there are in an adjunct position (e.g. John saw Mary here/there) the locative determiner is adjoined to VP ([vP VP here]) and subsequently moved to the Spec of PP, triggering the non-pronunciation of the preposition.
a. $[\quad[\mathrm{AT} / \mathrm{TO}$ here $]$
b. [here $[\mathrm{AT} / \mathrm{TO}$ here $]]$
c. They stayed (*at) here.

Collins (2007) argues further that home is similar to here/there with respect to its syntactic constituent structure. Thus, the same operations that apply in the derivation of locative determiners apply in the derivation of locative light nouns such as home, (10a,b). However, in the case of home, the pronunciation of the preposition is optional, compare $(9 \mathrm{c})$ to $(10 \mathrm{c})$.
a. $[\quad[\mathrm{AT} / \mathrm{TO}$ home $]]$
b. [home $[\mathrm{AT} / \mathrm{TO}$ home $]]$

2 This is also the case for the Condition (i) proposed in Di Sciullo (2005) on the linearization of affixes and roots. (i) The Specifier or the Head of a minimal tree must be legible at the Sensori-Motor interface.

The condition in (i) reduces the options for the linearization of affixes, on the basis of whether they occupy the Specifier or the Head of a minimal tree. In Asymmetry Morphology, affixes and roots are part of minimal trees where they occupy the edge of the tree, either the Specifier or the Head position. Morphological merger combines two minimal trees where all affixes are generated in the left of roots. When the Specifier does not host phonetic features the minimal tree flips to the right reordering the affix to the right of the root. This is the case for predicate affixes, such as -er and-able. This is not the case for locative and directional affixes, such as $-a$ and $-e n$, which occupy the Specifier of their minimal tree. The linearization procedure derives the linear order of affixes and roots for language with concatenative morphology, such as English and Italian, but also the ordering of affixes in tone language, such as Yekhee, émà-wò 'drinkable' wò 'drink' (Ye.), as well as languages with vowel harmony, such as Turkish, seç-im 'election', seç 'elect' (Tu.). See Di Sciullo (2005) for discussion. 
c. I stayed (at) home.

This analysis brings further support to the presence of unpronounced elements in syntax, and to the incidence of principles of efficient computation in their derivation. However, it leaves open the question of why here/there must move to the Specifier of AT/TO in English and why this movement is 'optional' with home.

In the next section, I discuss the properties of Fallese locative determiners and nouns such as 'case' (home) and contrast their properties with their Italian and English counterparts.

3. Locative determiners in Fallese. In Fallese the prepositional head of locative determiners can be pronounced. This is not the case for their Italian and English counterparts. The pronunciation of the preposition in Fallese locative determiners provides direct evidence that they are PPs. Furthermore, when the preposition is not pronounced, locative determiners in Fallese are PPs. This is evidenced by the fact that, like their Italian and English counterparts, they may occupy the complement position of locational or directional verbs, as it is the case for PPs but not for DPs (11); they can be conjoined with PPs and not with DPs, (12); they may be questioned by a wh-PP, and not by wh-DPs, (13).
a. $\quad$ È rimaste/iute (a)llocche/a lu Falle. (Fa.)
is stayed /went (at)there/ at/to the Fallo
'He stayed/went there/at Fallo.'
b. È rimasto/andato li /a Fallo. (It.)
is stayed /went there at/to Fallo
'He stayed/went there / to Fallo.'
(12) a. '̀ rimaste/state (a)ecche e a lu Falle. (Fa.)
is stayed /went at/to there and at/to Fallo
'He stayed /went there and at/to Fallo.'
b. È rimaste/andato li e a Fallo (It.)
is stayed/went there and at/to Fallo
'He stayed/ went there and at/to Fallo.'
(13) a. *(A)ddo/* Che si rimaste/iute? (Fa.)
at where/ what SELF be/went
b. Dove/*Che sei rimasto/andato? (It.)
where/what SELF stayed/went
'Where did you stay/go?'

Furthermore, locative determiners in Fallese, (a)ecche (here) and (a)llocche (there), are similar to home, with respect to the optional pronunciation of the prepositional head, (at) home.

However, the prepositional head must be obligatorily pronounced with Fallese case (home) as well as with Italian casa (home), (14), (15), which can be analyzed as bare nouns, with an impoverished DP structure, lacking plural and adjectival modification, (15). ${ }^{3}$ Thus, Fallese case and Italian casa would be bare nouns and not light nouns, as it is the case for the English home. ${ }^{4}$
a. È rimaste/iute *(a) case. (Fa.)
b. È rimasto/andato *(a) casa. (It.)

\footnotetext{
${ }^{3}$ See Pérez-Leroux and Roeper (1999) on bare nouns.

${ }^{4}$ See Kishimoto (2000) on light nouns.
} 
c. He stayed/went (at) home.

(15) a. *È rimaste/iute a cases. (Fa.)

'He is stayed/went at homes.'

b. * $\quad$ È rimasto/andato a bella casa. (It.)

is stayed/went at nice home

'He stayed/went at nice home.'

3.1 COMPLEMENT ADJUNCT ASYMMETRY. We observe that the variation in pronunciation of the preposition in Fallese locative determiners is not random. These facts indicate that there is a complement-adjunct asymmetry in the pronunciation/silence of the preposition in Fallese locative determiners that we illustrate below.

When the locative determiner is in complement position, the pronunciation of the preposition is optional, as illustrated below in (16) and (17). In (16), the locative determiner occupies the complement position of a locative or a directional verb, and in (17), it occupies the PP complement of a double object verb. In such cases, both ecche and aecche, locche and alocche are used.

Complement of locative/directional verb:

(16) a. È rimaste (a)ecche. (Fa.) is stayed (at) here

(ecche/aecch, locche/alloche are normally used 'He stayed there.'

b. È iute (a)locche. is went (at) there 'He went there.'

Complement of a double object verb:

(17) a. Ha misse la lettere (a)ecch. (Fa.) has put the letter at here 'He put the letter here.'

b. Ha purtate la scatole (a)locche. has brought the box at there 'He brought the box there.'

However, when the locative determiner is in an adjunct position, the preposition must be pronounced. This is the case for wh-PPs, (18), which are merged outside of the verbal projection. This is also the case when the locative determiner is an adjunct to an unaccusative, an unergative, a transitive verb, or a double object verb, (19)-(22).

Wh-adjunct to a locative/directional verb:

a. $\quad *(A)$ ddò si state?' (Fa.) (addò is normally used vs. Italian dove) at where you stayed 'Where did you stay?'

b. $\quad *(\mathrm{~A})$ ddò si iute? at where you went 'Where did you go?'

Unaccusative verb 

a. È ariviete aecche. (Fa.) 'He stayed here.'
b. È partite alocche. (Fa.) 'He left there.'

(Normally used with the preposition pronounced but ecche is also attested : quann'arivè ecche)

Unergative verb
(20) a. Ha durmite alocche. (Fa.) 'He slept there.'
(Normally used with the preposition pronounced)
b. Ha camminiete alocche. 'He walked there.'

Transitive verb

(21) a. Ha 'ncuntrate Anne alocche. (Fa.)

has met Anne there 'He/She met Anne there.'

b. Ha viste Anne alocche. has seen Anne there 'He/She saw Anne there.'

Double object verb

(22) a. Ha scrite na lettere a Gianni alocche. (Fa.) has written a letter to Gianni there 'She/He wrote a letter to Gianni there.'

b. Ha spedite na lettere a Gianni alocche has sent a letter to Gianni there 'She/He sent a letter to Gianni there.'

We summarize the facts in the following table:

\begin{tabular}{|c|c|c|c|c|c|}
\hline Verb & Loc/Dir & Unaccusative & Unergative & Transitive & Ditransitive \\
\hline & \multicolumn{3}{|c|}{ Complement } & \multicolumn{2}{|c|}{ Adjunct } \\
\hline $\mathrm{AT} / \mathrm{TO}$ & & & & & \\
\hline pronounced & $\sqrt{ }$ & $\checkmark$ & $\checkmark$ & $\checkmark$ & $\checkmark$ \\
\hline silent & $\sqrt{ }$ & $\sqrt{ }$ & $\checkmark$ & & \\
\hline
\end{tabular}

The complement adjunct asymmetry with respect to the pronunciation/silence of the prepositional head in Fallese locative determiners does not come as a surprise. Variation is an effect of experience given the computational procedure of the language faculty, which is structure dependent. In the next section, we present an analysis of the observed micro-variation.

3.2 Proposed Analysis. We propose that the micro-variation in the pronunciation/silence of the preposition in Fallese locative determiners follows from a minimal derivational difference, given independent properties of the computational procedure of the language Faculty, including Merge (External and Internal) and feature valuing.

3.2.1 LOCATIVE DETERMINERS. We assume that functional elements are associated with formal features, which can be valued $([\mathrm{F}])$ or unvalued $([\mathrm{uF}])$, and that unvalued feature must be valued in the syntactic derivation (Pesetsky \& Torego 2004). We assume further that feature valuing is done under Agree, which is defined in terms of the proper subset relation (Di Sciullo 
2005). We take prepositions to be associated with the valued prepositional feature [P]. We also take prepositions to be associated with an unvalued $u$ Determiner feature, $[u \mathrm{D}]$, to be valued in the course of the derivation. This feature is required independently, for the merger of verbs with their DP complement (Di Sciullo \& Isac 2008). AT and TO are specified for [uD], given that locative determiners are pronouns, and that pronouns are determiners (Postal 2004). AT is also specified for the valued locative [LOC] feature and TO is also specified for a directional feature [DIR]. The features [DIR] and [LOC] are needed independently in the derivation of complex verbal structures, including prepositional prefixes, as discussed in Di Sciullo (2005). Furthermore, locative determiners are deictic pronouns, thus they are specified with the valued features proximal [PROX], in the case of here, and distal [DIST], in the case of there. Both here and there are specified for the valued feature deictic [DEIC]. As discussed so far, the feature specifications of AT and TO, as well as the feature of here and there are the following:
(23) a. AT: $\{[\mathrm{P}],[\mathrm{uD}],[\mathrm{LOC}]\}$
b. TO: $\{[\mathrm{P}],[\mathrm{uD}],[\mathrm{DIR}]\}$
(24) here : $\{[\mathrm{D}],[\mathrm{LOC}],[\mathrm{PROX}],[\mathrm{DEIC}]\}$
b. there : $\{\mathrm{DD}],[\mathrm{LOC}],[\mathrm{DIST}],[\mathrm{DEIC}]\}$

We propose to derive the micro-variation between Fallese and Italian in the pronunciation/silence of the preposition in locative determiners as follows. While the [uD] of AT/TO must be valued in the derivation, and this valuation can be done either via External or Internal Merge, (25a,b), but only via Internal Merge in Italian, (25b). Given Collins' (2007) Spell-out Condition, it follows that AT/TO will be pronounced in Fallese, when Internal Merge did not apply, (25a), and it will not be pronounced when Internal Merge did apply, (25b), since the specifier position will be filled. In contrast, AT/TO is never pronounced in Italian (and English), as the choice between Internal or External Merge for feature valuation has been eliminated, and only the derivation is $(25 \mathrm{~b})$, where $[\mathrm{uD}]$ is valued by Internal Merge, is available. ${ }^{5}$

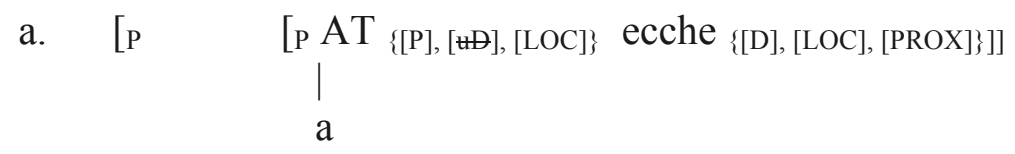

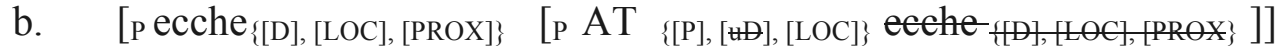

We observe above that AT/TO may be pronounced when the locative determiner is in complement position, whereas it must be pronounced when the locative determiner is in adjunct position. This complement adjunct asymmetry follows from the properties of the computational system, including phase asymmetry, in conjunction with principle of efficient computation.

When the locative determiner is in complement position, we correctly predict that in Fallese, the prepositional head may or not be pronounced, (16)-(17), given that feature valuing can be done either by External Merge or Internal Merge. In adjunct position, the preposition must be pronounced, (18)-(22). As adjuncts are merged to the Specifier of an extended functional projection, we will take locative determiners in Fallese to be built by the simplest derivation, that is by External Merge. The result of the derivation is itself externally merged to the Specifier of a

\footnotetext{
${ }^{5}$ Feature valuing via Internal Merge for English is support by the displacement of here/there to the Specifier of the preposition for other prepositions than Locative and Directional prepositions, which are still pronounced in Modern English, e.g. here with, there for.
} 
functional projection such as DeicticP, assumed in Cinque and Rizzi (2010), (26), to value the unvalued deictic feature of the head of DeicticPP, $(27) .^{6}$

[PPdir [PPstat AT [DPplace [DegP [ModeDirP [AbsViewP [RelViewP source/goal/path stative AT measure diagonally north/south up/down

[RelViewP [DeicticP [AxPartP [PP P [NPplace [PLACE]]]]]]]]]]] in/our here/there under/over/behind Ground

DeicticPP

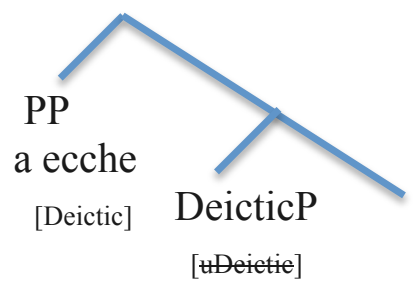

Independent evidence for such a derivation comes from the fact that a DP must be previously derived before it is merged to $\mathrm{V}$ or to $\mathrm{v}$, otherwise the derivation will cancel, as discussed in Di Sciullo and Isac (2008).

3.2.2 COMPLEX LOCATIVE DETERMINERS. Furthermore, micro-variation in the pronunciation/silence of the preposition is also observed in Fallese complex locative determiners, such as aecche $a$ monte (up here) and alloche a bal (down there), (28). In complement position, while the prepositional head of the locative determiner can be pronounced or remain silent, the prepositional head of the lower PP must be pronounced, and PLACE is spelled out as the light noun bal (valley) or monte (mountain), (29).

(28) a. È rimaste (a)ecche * (a)bal $(\mathrm{Fa}) /$ li giù. (It) is stayed at-here at valley / there down 'He stayed down here.'

b. È rimaste (a)locche * $(\mathrm{a})$ monte $(\mathrm{Fa}) /$ li sù. (It) is stayed at-there at mountain / there up 'He stayed up there.'

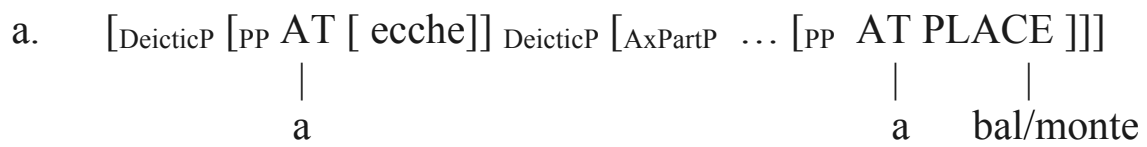

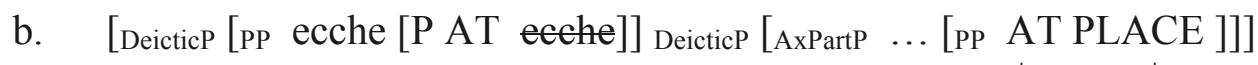<smiles></smiles>

Bal and monte are light locative nouns in Fallese complex locative determiners, as it is typical of other locative light nouns, such as home, discussed in Collins (2007). They do not have a functional DP structure. Thus, they do not take determiners, they cannot be modified by adjectives and they cannot appear in the plural, (30).

${ }^{6}$ See also Svenonius (2010) for extended projections of P. 
a. $\quad$ È rimaste (a)ecche a (*lu) bal/lu monte. is stayed at-here to the valley/the mount 'He stayed at the down here/up here.'

b. È rimaste (a)loche a (*lu bielle) bal/monte. is stayed at-there at the nice valley/mount 'He stayed at the nice down there/up there.'

c. È rimaste (a) ecche a (*1i) bali/monti is stayed at here the-PLUR valleys/mounts 'He stayed at the downs there/ups there.'

The preposition $a$ must be pronounced in PPs with locative light noun case in Fallese, likewise for light locative nouns bal and mont in complex locative determiners.

3.3 Section SUMMARY. Locative determiners are PPs notwithstanding the fact that their prepositional head can be silent in some cases. In Italian and English, the preposition is unpronounced. Italian qui/li as well as English here/there obligatorily move to specifier of $\mathrm{AT} / \mathrm{TO}$ to value the unvalued $\mathrm{uD}$ feature of the prepositional head. Given that the Specifier of the locative determiner is filled, the preposition $a$ is not pronounced, (31).

$\begin{array}{ll}\text { (31) a. } & \text { [SPEC qui }[\text { HeAd AT/TO qui }]] \\ \text { b. } & \text { [SPEC li }[\text { HeAd AT/TO li }]]\end{array}$

In Fallese ecche/locche the prepositional head is pronounced more often than not. It is 'optionally' pronounced when it is in complement position. This follows, according to our proposal, from the possibility to value unvalued features either by Internal Merge or by External Merge in Fallese locative determiners. The preposition $a$ is pronounced when feature valuing is done via External Merge, and the Specifier position is not filled, (32a). The preposition is not pronounced when feature valuing is done via Internal Merge, (32b).
a. $[\mathrm{SPEC}$

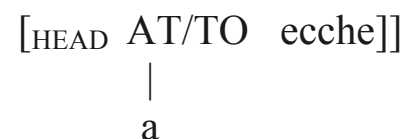
b. [SPEC ecche [HEAD AT/TO ecche]]

Thus, the apparent optionality in the pronunciation of AT/TO in Fallese follows from a property of the computational procedure of the Language Faculty: a choice point in feature valuing by Internal Merge or by External Merge, given principles reducing complexity including Spell-out Conditions. The fact that the prepositional head of the locative determiner in Fallese must be pronounced when the locative determiner is in adjunct position follows from the structure of the extended functional projection, where already built locative determiners are merged in the Specifier of a functional head. In Fallese, in more complex locative determiners, the prepositional head of light nouns, such as bal and monte must be pronounced, as it is the case with bare nouns, such as case.

The next section identifies the predictions of our analysis, which relies on the feature specifications of functional categories and their feature valuing in the course of their derivation.

4. Predictions. Micro-variation is tied to the feature specification of lexical items, functional heads and other constituents. We identify the predictions of our analysis for the 
pronunciation/silence of the preposition in other functional categories than locative determiners. The internal structure of these functional categories does not include a [D] feature to value the unvalued determiner feature $[u \mathrm{D}]$ of AT/TO. Moreover, they do not have the locative or directional valued features to match with those of the preposition. Consequently, the proper subset requirement on feature valuing does not obtain.

4.1 PRONUNCIATION/SILENCE OF OTHER CATEGORIES THAN LOCATIVE DETERMINERS. Our analysis makes predictions for the pronunciation/silence of other categories than locative determiners. It correctly predicts that the preposition $a$ is pronounced only with wh-PP addò (where) in Fallese, (33a), (34 a); whereas it is not pronounced in Italian, (33b), (34b). The wh-PP where differs from locative determiners here and there only with respect to the [wh] feature, see Di Sciullo (2005). It is an adjunct wh-PP, and like other adjunct locative determiners, the preposition must be pronounced.
a. addò, $(* a)$ quande, $(* a)$ picche, $(* a) q u a l e,(* a)$ chi, $(* a)$ che (Fa.)
'at-where, at-when, at-why, at-which, at-who, at-what'
b. dove, quando, perchè, quale, chi, che (It.)
'where, when, why, which, who, what, whose'

(34) a. Addò li mittive, alocche zi stave. (Fa.)

at-where him put, at-there him+REFL stayed

'where you put him, there he stayed.'

b. Dove lo mettevi li si stava. (It.)

where him put there him+REFL stayed

'Where you put him, there he stayed'

Furthermore, our analysis correctly predicts that the preposition $a$ is pronounced in Fallese comparative demonstratives accusi (like this) acculi (like that); whereas it remains silent in Italian, cosi (like this), coli (like that). The demonstrative this and that have the feature specifications to satisfy the proper subset relation and thus asymmetrical agreement with the preposition $a$. Furthermore, comparative demonstrative do not occupy a complement position, and thus the preposition $a$ must be pronounced in Fallese; whereas it is not pronounced in Italian, (35).

(35) a. Chiamàtele accuscì e chiamàtele accullì. (Fa.) name him at-like this and name him at-like that 'name him like this and name him like that.'

b. Chiamatelo cosi e chiamatelo coli. (It.) name him like this and name him like that.' 'name him like this and name him like that.'

Moreover, given that complementizers are not specified for the $[\mathrm{uD}]$ and the $[\mathrm{LOC}] /[\mathrm{DIR}]$ features (Di Sciullo 2005), and that $c a$ is a complementizer in Fallese, we also predict that * $a c a$ is not found in Fallese, (36).

(36) a. Diceme $(* a)$ ca $i$ e te chiacchiarijeme. (Fa.)

say that I and you chatting

'Let's say that we are chatting.'

b. Diciamo che io e te stiamo chiacchierando. (It.)

say that me and you are chatting

'Let's say that we are chatting.' 
4.2 Diachronic DEVElopment. The micro-variation in the pronunciation/silence of the preposition in locative determiners can be linked to the diachronic development of Italian and Fallese from Latin, as mentioned in section 1. The proposed analysis also makes predictions with respect to the diachronic development of locative determiners of Italian and Fallese from Latin.

Variation requires experience (Chomsky 2005, 2013, 2014), viz., the intervention of external factors to the language faculty, including language acquisition, languages in contact and pragmatic factors. We predict that the apparent optional pronunciation of the preposition AT/TO in locative determiners may arise at different points in language diachrony. This is the case in the development of locative determiners from Latin ad ille 'at there' to Modern Italian $l i$ 'there', as well as illo loco 'at that place'. The apparent optional pronunciation of AT/TO in Fallese follows from a choice point in the derivational procedure of the Language Faculty. We predict that the apparent optional pronunciation of AT/TO may arise at different points in language diachronic development. This is the case in the development of locative determiners from Latin ad locus 'there', to Fallese (a)locche and to Modern Italian $l i$ 'there'. For example, in different stages of Latin, ad locum is also used as a noun without the preposition, (37), and ad hic (here) is used without the preposition, as demonstrative, (38). See Di Sciullo and Somesfalean (in preparation) for further discussion.

(37) a. Prodest quorum in locum ac numerum pervenire velis ab iis ipsis illo loco (Lat.) 'Their profits are in place and the number you wish to reach them from that place' (Cicero, Commentariolum Petitioni)

b. ... locum magnum super ripam fluminis ... (Lat.)

'great place on the bank of the river' (Cicero, Historia Brittonum)

a. ... si igitur haec sunt stupenda ... (Lat.)

'therefore if these are amazing'

(Edesseni: Tractatus de Nativitate Domini Nostri Christi)

b. Nescio quid hic rei est.

'I don't know what this thing is.'

(Petrarca, Contra Medicum Quendam)

Independent evidence for the diachronic change in the pronunciation/silence of the proposition in locative determiners comes form the diachronic development of the comitative P-Pronoun structures, from Latin cum me, me cum 'with me, me with', to Old Italian con me co 'with me with', to modern Italian con me, 'with me' where the lower preposition co is no longer pronounced (Di Sciullo et al, in press).

Given language acquisition and languages in contact, variation can be further explained in terms of the interaction of the grammar internal computational procedure with third factor principles of efficient computation (Di Sciullo and Jenkins 2016). We investigated the consequences of the hypothesis that symmetry breaking, as a principle of efficient computation, could contribute to explain the diachronic variation in the order of a functional category with respect to its complement. This is the case for the development of the possessive pronouns in Italian form the genitive case in Latin (Di Sciullo 2011), for the development of adpositions to prepositions in the development of the Indo-European Language (Di Sciullo and Nicolis 2013, Di Sciullo et al, in press), as well as in the development of the definite determiner from Old to Modern Romanian (Di Sciullo and Somesfalean 2013), and in the development of complex 
cardinal numerals from Latin to Italian (Di Sciullo 2016). We argued that, in the development of prepositional demonstrative and determiner structures, choice points in the computational procedure of the language faculty tend to be eliminated gradually. This can also be seen in the development of locative determiners in form Latin to Fallese and to Italian. The data from Fallese locative determiners further confirms that points of symmetry may persist through time in some languages, while they are eliminated in other modern variants of the languages, as an effect of principles of efficient computation. Symmetry breaking and Spell-Out conditions relying on the Specifier-Head asymmetry, as well as cyclical complement non-complement Spell-Out, such as Derivation by phases, can be subsumed under a more general class of principles of efficient computation of Maximizing Asymmetry (Di Sciullo 2016).

4.3 SECTION SUMMARY. In this section we identified the predictions of our analysis for the pronunciation/silence of the preposition in other functional categories than locative determiners in Fallese and in Italian. We also suggested that a possible explanation of the micro-variation discussed in this paper on the form of locative determiners would be to attribute to third factor principles of efficient computation both the variation in the displacement and the pronunciation/ silence of functional heads.

5. Summary and consequences. Micro-variation is observed in the pronunciation/silence of the propositional head of locative determiners in Fallese, which is not observed in Italian or in English, where the preposition is always silent. We raised questions left unanswered by previous analyses of locative determiners in English. They leave open the question of why here/there must move to the Specifier of AT/TO in English, and thus the preposition is silent, and why this movement is 'optional' with home, and thus the preposition may optionally be pronounced. We proposed that the micro-variation observed in Fallese locative determiners follows from a minimal difference in feature valuing.

We first provided empirical evidence that locative determiners in Fallese, like their Italian and English counterparts, are PPs, even when their prepositional head is not pronounced. We showed further that the preposition is optionally pronounced when the locative determiner is a complement of a verbal projection, whereas it is obligatorily pronounced when it is an adjunct to a verbal projection. Assuming that micro-variation is linked to the feature specification of a functional head, we proposed to derive the apparent optionality of the preposition from the possibility in Fallese to value the unvalued feature $[u \mathrm{D}]$ either by External Merge or by Internal Merge in conjunction to Collins' (2007) Spell-Out Condition. We proposed further that, when the locative determiner is in an adjunct position, the obligatory pronunciation of the preposition follows from the architecture of the extended functional projection. Thus, the complementadjunct asymmetry with respect to the pronunciation/silence of the preposition in locative determiners follows from the computational procedure of the language faculty in conjunction with Spell-out conditions, which we take to fall into Third factor principles of efficient computation. The proposed analysis of the pronunciation/silence of the preposition in Fallese locative determiners has both theoretical and empirical. Predictions on the form of the other functional categories in Fallese and in Italian were identified, as well as predictions on the diachronic development of locative determiners from Latin to Fallese and to Italian.

Our proposal has consequences for linguistic theory and language variation. Our proposal further supports the Minimalist Program, as the micro-variation in the pronunciation/silence of the prepositional head in determiners in Italian and English vs. Fallese, and its apparent optionality in Fallese follow from the theory, including the computational procedure of the 
Language Faculty and Third factor principles of efficient computation. We summarize our findings as follows:

i) a single operation derives the variation in the displacement as well as in the pronunciation/silence of constituents;

ii) apparent optionality of a constituent follows from choice points in the computational procedure of the Language Faculty, namely feature valuing via External Merge or Internal Merge;

iii) third Factor Principles, falling into the class of Maximize Asymmetry Principles, play a role in further explaining micro-variation.

Our proposal also contributes to the Biolinguistic Program, as it provides a link between language variation and variation in biology. Maximize Asymmetry Principles reduce choice points in the derivation and the externalization of linguistic expressions. Such Principles are akin to natural laws discussed in the development of the shape of bipartite biological organisms, as discussed in Palmer (2004, 2005) and Di Sciullo and Jenkins (2016) among others.

\section{References}

Cinque, Guglielmo \& Luigi Rizzi. 2010. Matching spatial PPs: an introduction. In Guglielmo Cinque Cinque \& Luigi Rizzi (eds.) Mapping spatial PPs. The cartography of syntactic structures, vol. 6. 3-15. Oxford, Oxford University Press.

Collins, Chris. 2007. Home sweet home. NYU working papers in linguistics 1: 1-34.

Chomsky, Noam 2014. Problems of projection: Extensions. Ms. MIT.

Chomsky, Noam. 2013. Problems of projection. Lingua 130. 33-49.

Chomsky, Noam. 2008. On phases. In Robert Freidin, Carlos Peregrín Otero \& Maria Luisa Zubizarreta (eds.), Foundational issues in linguistic theory. Essays in honor of Jean-Roger Vergnaud. 133-166. Cambridge, MA: MIT Press.

Chomsky, Noam. 2005. Three factor in Language design. Linguistic Inquiry. 36(1). 1-22.

Chomsky, Noam. 2001. Beyond explanatory adequacy. In MIT occasional papers in linguistics 20. MIT working papers in linguistics.

Chomsky, Noam. 1995. The minimalist program. Cambridge, MA: The MIT Press.

Chomsky, Noam. 1981. Lectures on government and binding. Dordrecht: Foris.

Di Sciullo, Anna Maria \& Stanca Somesfalean. In preparation. The development of locative determiners in the Romance languages.

Di Sciullo, Anna Maria, Marco Nicolis \& Stanca Somesfalean. In press, 2017. Commitative $P$. In Jacobo Garzonio \& Silvia Rossi (eds.), Variation in prepositions. Oxford Studies in Comparative Syntax. Oxford University Press.

Di Sciullo, Anna Maria \& Lyle Jenkins. 2016. Biolinguistics and the human language faculty. Language. Volume 192, 3: e1-e32.

Di Sciullo, Anna Maria. 2015. On the domain specificity of the human language faculty and the effects of principles of computational efficiency: contrasting language and mathematics. Revista LinguiStica: 28-56.

Di Sciullo, Anna Maria \& Stanca Somesfalean. 2013. Variation in the position of the definite determiner in romanian: A biolinguistic perspective. Romance linguistics in the Pacific: Variation in time and space. Special issue of the Australian Journal of Linguistics 33(2): 
121-139. Taylor \& Francis.

Di Sciullo, Anna Maria \& Marco Nicolis. 2012. Third factor principles and the development of P. North East Linguistic Society 42. University of Toronto.

Di Sciullo, Anna Maria. 2011. A Biolinguistic approach to variation. In Anna Maria Di Sciullo \& Cedric Boecks (eds.), The biolinguisticeEntreprise: New perspectives on the evolution and nature of human language faculty. 305-326. Oxford: Oxford University Press.

Di Sciullo, Anna Maria \& Dana Isac. 2008. The asymmetry of merge. Biolinguistics 2: 260-290.

Di Sciullo, Anna Maria 2005. Asymmetry in morphology. Cambridge, Mass: The MIT Press.

Katz Jerrold J. \& Paul M. Postal. 1964. An integrated theory of linguistic descriptions. Cambridge: MIT Press.

Kayne, Richard. 2006. On parameters and on principles of pronunciation. In Hans Broekhuis et al. (eds.), Organizing grammar: Linguistic studies in honor of Henk van Riemsdijk. 289299. Berlin: Mouton de Gruyter.

Kayne, Richard. 2005. Movement and silence. Oxford: Oxford University Press.

Kishimoto, Hideki. 2000. Indefinite Pronouns and Overt N-Raising. Linguistic Inquiry 31: 557-566.

Koopman, Hilda \& Anna Szabolcsi. 2000. Verbal complexes. Cambridge: MIT Press.

Liao, Wei-wen Roger \& Dingxu Shi. 2013. To pronounce or not to pronounce: locating silent heads in Chinese and English. Studies in Chinese Linguistics. Volume 34, Number 1:55-65.

McCawley, James. 1988. Adverbial NPs: Bare or clad in see-through garb? Language 64.3: 583590.

Palmer, Richard. 2005. Antisymmetry. In Benedikt Hallgrímsson \& Brian K. Hall (eds.), Variation: A central concept in biology. 359-398. Burlington: Elsevier.

Palmer, Richard 2004. Symmetry breaking and the evolution of development. Science 306. 828-833.

Pérez-Leroux, Ana \& Thomas Roeper. 1999. Scope and the Structure of Bare Nominals:

Evidence from Child Language. Linguistics 37-5: 927-960.

Pesestsky, David \& Esther, Torrego. 2004. The syntax of valuation and the interpretability of features. In Simin Karimi, Vida Samiian and Wendy K. Wilkins (eds.), Phrasal and clausal architecture: Syntactic derivation and interpretation. 262-294. Amsterdam: John Benjamins. http://web.mit.edu/Linguistics/people/faculty/pesetsky/Pesetsky_Torrego_Agree_paper.pdf

Postal, Paul. 2004. Skeptical linguistic essays. Oxford: Oxford University Press.

Riemsdijk, Henk Van. 1978. A case study in syntactic markedness: the binding nature of prepositional phrases. Dordrecht: Foris Publications.

Svenonius, Peter. 2010. Spatial P in English. In Guglielmo Cinque Cinque \& Luigi Rizzi (eds.) Mapping spatial PPs. The cartography of syntactic structures, vol. 6. 127-160. Oxford, Oxford University Press.

Online resources:

http://thelatinlibrary.com/

http://www.perseus.tufts.edu/hopper/collection?collection=Perseus $\% 3$ Acorpus $\% 3$ Aperseus

\%2CLatin\%20Texts

http://vocabolario.sns.it/html/_s_index2.html 